\title{
The Relative Expression of Human Histone H2A Genes Is Similar in Different Types of Proliferating Cells
}

\author{
CECILIA MANNIRONI, ${ }^{1}$ ANN ORR, CHRISTOPHER HATCH, ${ }^{2}$ DUANE PILCH, \\ VESSELA IVANOVA, and WILLIAM BONNER
}

\begin{abstract}
To help elucidate the factors regulating the expression of histone multigene families in proliferating cells, we asked whether the relative expression of different members of such a family was dependent upon or independent of the type of proliferating cell. This question was examined by measuring the relative expression of seven members of the human histone H2A multigene family in four cell lines of diverse origin. Two previously uncharacterized members of the $\mathrm{H} 2 \mathrm{~A}$ gene family were found to be the most abundantly expressed of the seven in all four cell lines. One of these encodes an H2A.2 species containing methionine. The lines examined in the study were Jurkat (a lymphoma line), $\mathrm{N}$-tera (a pluripotent embryonic carcinoma line), HeLa (originally isolated as a cervical carcinoma), and IMR90 (a normal embryonic fibroblastic line). The amount of each mRNA species was quantitated using oligonucleotides about 30 bases long complementary to the $5^{\prime}$ or $3^{\prime}$ untranslated regions. In each cell line, there was at least an eight-fold difference in the amount of the most and least highly expressed of the seven H2A mRNA species. In addition, there were up to five-fold differences among the cell lines in the amount of the H2A mRNA species as a fraction of total RNA. However, in contrast to those differences, the four cell lines were found to express the seven H2A mRNAs in similar relative amounts. These findings suggest that the relative expression of the individual members of a histone gene family is independent of the type of replicating cell.
\end{abstract}

\section{INTRODUCTION}

$\mathbf{E}$ UKARYOTIC Cells contain a multiplicity of histone genes that are probably expressed at some level in all cells of an organism. Histone gene expression has been found in germ line cells (Challoner et al., 1989; Moss et al., 1989; Huh et al., 1991), and at low rates in differentiated and quiescent somatic cells (Wu et al., 1982, 1983; Pantazis and Bonner, 1984) as well as in proliferating somatic cells. In the latter, replication-linked as well as several relication-independent histone genes are expressed. The former have been localized to clusters on chromosomes 1, 6, and 12 (Tripputi et al., 1986) and exhibit several characteristic features (Wells and McBride, 1989; Wells and Brown, 1991). The genes lack introns and contain two conserved sequences, a stem-loop motif and a U7 snRNP binding motif, both within 100 bases downstream of the translation termination codon. These two motifs are utilized in processing the $3^{\prime}$ end of the replication-linked histone mRNAs to terminate just downstream of the stemloop (reviewed by Heintz, 1991 and Osley, 1991). In addition, the rates of transcription of the replication-linked histone genes and the stabilities of their mRNAs are modulated by the rates of both DNA replication (Heintz et al., 1983; Sittman et al., 1983; Bandyopadhyay et al., 1987; Bonner et al., 1993) and protein synthesis (Stimac et al., 1984; Baumbach et al., 1984; Wu and Bonner, 1985; Graves et al., 1987).

In addition to these replication-linked histone genes, there are also several replication-independent histone genes expressed in proliferating somatic cells. Two of these genes, the H3.3 (Wells and Kedes, 1985) and the H2A.Z (Dalton et al., 1989; Hatch and Bonner, 1990) contain introns, lack the stem-loop and U7 snRNP binding se-

\footnotetext{
Laboratory of Molecular Pharmacology, Developmental Therapeutics Program, Division of Cancer Treatment, National Cancer Institute, National Institutes of Health, Bethesda, MD 20892.

'Present address: Instituto di Biologie Cellulare, Consiglio Nazionale delle Ricerce, Viale Marx 43, 00137 Rome, Italy.

2Present address: Journal of the National Cancer Institute, 9030 Old Georgetown Road, Bethesda, MD 20814.
} 
quences, and produce polyadenylated transcripts. A third gene, the H2A.X, is unusual for a replication-independent gene because it lacks introns and produces a stem-loop mRNA, as do the replication-linked histone genes; however, the production of H2A.X protein is only slightly linked to DNA replication (Bonner et al., 1993). The two $\mathrm{H} 2 \mathrm{~A}$ replication-independent genes, $\mathrm{H} 2 \mathrm{~A} . \mathrm{X}$ and H2A.Z, are proliferation dependent; their expression is greatly decreased in nonproliferating cells. In contrast, the H3.3 gene is both replication and proliferation independent.

An unknown number of the approximately 20 members of each histone gene family are expressed in different types of replicating cells. It is also not known whether the relative expression of each member of a histone gene family is similar in various replicating cell types of an organism or whether these members may be expressed to different relative extents in different cell types. There is evidence that certain histone genes are highly expressed in certain cell lines (Hurt et al., 1989). In addition, there are diverse elements in the distal portions of the promoters of different members of a histone gene family (Heintz, 1991), elements that may function to regulate tissue- or cell-type-specific expression of those genes.

To understand how the expression of the approximately 20 members of each histone gene family may be coordinated in proliferating cells, we have studied the expression of seven human $\mathrm{H} 2 \mathrm{~A}$ genes in four proliferating cell lines. Because of the high sequence conservation among the coding regions of different members of a histone gene family, oligonucleotides about 30 bases long complementary to the $5^{\prime}$ and $3^{\prime}$ nonconserved untranlated regions of the mRNAs of these seven members of the human histone $\mathrm{H} 2 \mathrm{~A}$ gene family were used to quantitate the mRNA concentrations. These seven $\mathrm{H} 2 \mathrm{~A}$ genes include two highly expressed members that have not been previously described. One of these two, named H2A.1b, encodes an $\mathrm{H} 2 \mathrm{~A} .1$ species lacking methionine while the other, named H2A.2, encodes an H2A. 2 species containing methionine. We found that in any one cell line, there was an approximately eight-fold difference in the amount of mRNA between the most and least highly expressed of these seven $\mathrm{H} 2 \mathrm{~A}$ genes. However, each of these genes was found to contribute a similar relative amount of H2A mRNA in the four cell types examined. These findings suggest that the expression of histone gene families in proliferating cells may be independent of the type of proliferating cell.

\section{MATERIALS AND METHODS}

\section{Isolation of $H 2 A .1 b$ and $H 2 A .2$ cDNAs}

A cDNA library was prepared from poly(A) mRNAs extracted from HeLa cell cultures that had been incubated with inhibitors of DNA replication to enrich for mRNAs encoding replication-independent histone species such as H2A.X (Mannironi et al., 1989). Clones were selected by hybridization to a human $\mathrm{H} 2 \mathrm{~A}$.1 a gene, previously cloned in this laboratory (Hatch, unpublished results), and identical to the H2A gene reported by Heintz et al. (1983). The clones were identified by partially sequencing them from the $5^{\prime}$ end. The H2A.1b and H2A. 2 cDNAs were isolated and sequenced by the Squenase (United States Biochemical Corp.) protocol using primers. The H2A.1b GenBank accession number is L19778; the H2A.2 number is L19779. Homologies to other genes were performed with the BLAST (Altschul et al., 1990) program of the National Center for Biotechnology Information accessed through the Advanced Scientific Computing Laboratory of NCI.

\section{Cell cultures}

The Jurkat cell line was grown in suspension in RPMI-1640 medium (Hazleton Biologics, Inc). The HeLa and N-tera cell lines (Andrews et al., 1984; gift of R. Thayer, Laboratory of Biochemistry, NCI, NIH) were grown as attached cultures in Dulbecco modified MEM (Advanced Biotechnology Inc.). The human fibroblastic line IMR90 was grown in Eagle's alpha-modified MEM (GIBCO Laboratories). All media were supplemented with $10 \%$ fetal calf serum; for IMR 90 , the serum was not heat inactivated. DNA synthesis was inhibited by incubating cell cultures with $10 \mathrm{mM}$ hydroxyurea diluted from a $1 M$ stock solution prepared in phosphate-buffered saline (PBS); protein synthesis was inhibited with $10 \mu \mathrm{g} / \mathrm{ml}$ cycloheximide diluted from a $10 \mathrm{mg} / \mathrm{ml}$ stock solution prepared in PBS. These concentrations resulted in reversible inhibition of DNA or protein synthesis and exponential growth in Jurkat cell cultures (Bonner et al., 1993).

\section{RNA preparation}

Total cellular RNA was prepared by the rapid method described in Sambrook et al. (1989). Purified RNA, usually $5 \mu \mathrm{g}$ per well, was electrophoresed in $1.2 \%$ agarose gels containing $3 \%$ formaldehyde with MOPS buffer (Sambrook et al., 1989). Gels were stained briefly with ethidium bromide to check 18 and 28S RNA integrity and constancy of sample loading. RNA was transferred by electroblotting to Zetaprobe membranes (Bio-Rad Laboratories), which were baked under vacuum for $0.5-1 \mathrm{hr}$ at $80^{\circ} \mathrm{C}$.

\section{Hybridization of Northern blots}

Synthetic oligonucleotides about 30 nucleotides long, complementary to the $5^{\prime}$ and $3^{\prime}$ untranslated regions of the five human replication-linked H2A mRNAs were used as probes for RNA blot analysis (Henderson et al., 1991). The oligonucleotides were designed to have a $T_{\mathrm{m}}$ of $65^{\circ} \mathrm{C}$ in $1 \times$ SSPE. The sequences for the oligonucleotides were derived from H2A.1a (Heintz et al., 1983; GenBank Accession \#X00089), H2A.1c (Dobner et al., 1991; GenBank Accession \#X57138), H2A.1d (Albig et al., 1991; GenBank Accession \#M60752), H2A.X (Mannironi et al., 1989; GenBank A.ccession \#X02885), and H2A.Z (Hatch and Bonner, 1988; GenBank Accession \#X06885). The oligonucleotides used are shown in Table 1. With the exception of the H2Acod3 oligonucleotide, these oligonucleotides all yielded single bands on Southern blots of Eco RI-digested human genomic DNA (Bios Corp.). The H2Acod3 oligonucleotide 
Table 1. Oligonucleotides Used for Hybridization Studies

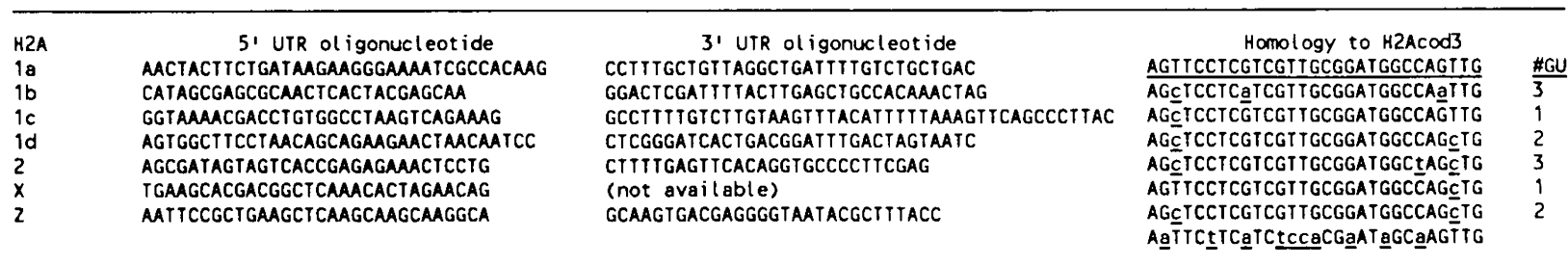

Oligonucleotides were complementary to the $5^{\prime}$ or $3^{\prime}$ UTR of the noted human H2A genes. It was not possible to design a 3' UTR oligonucleotide for the H2A.X mRNA that met the criteria as described in Materials and Methods. The H2Acod3 oligonucleotide is complementary to the mRNA encoding amino acids 84-93 of H2A genes; this sequence is highly conserved in all these H2A mRNAs except the H2A.Z. Except for the H2A.Z, the sequence differences could be accommodated by GU pairs, the number of which is listed at the right (\#GU).

was complementary to the region encoding amino acids 84-93 (Table 1) of six H2A mRNAs with no mismatches other than one to three GU pairs with each $\mathrm{H} 2 \mathrm{~A}$ sequence. An oligonucleotide, CTTGTAGATCTGTGTGTTCCGGTCCCAATAC, complementary to bases 246-276 of human class I HLA-B7 mRNA (GenBank Accession \#M35444) was used to determine the amounts of this nonhistone mRNA.

Oligonucleotides were 5 '-end-labeled (kit from Boehringer Mannheim Biochemicals) with $\left[\gamma^{-{ }^{32}} \mathrm{P}\right] \mathrm{ATP}(6,000$ $\mathrm{Ci} /$ mmole, DuPont NEN), and purified through NucTrap Push Columns (Stratagene Cloning Systems). The Northern blots were prehybridized for several hours and hyubridized overnight at $57^{\circ} \mathrm{C}$ according to the method of Henderson et al. (1991), except that nonfat milk was not added to the hybridization solution. The posthybridization washes were also modified from their procedures; the filters were rinsed in three plastic dishes with $1 \times$ SSPE, $0.5 \% \mathrm{NaDodSO}_{4}$ at room temperature, and then washed with $0.1 \times \mathrm{SSPE}, 0.5 \% \mathrm{NaDodSO}_{4}$ for $30 \mathrm{~min}$ at $47^{\circ} \mathrm{C}$. Quantitative analysis of hybridized membranes was performed on the Betagen analyzer.

\section{Quantitation of $m R N A$ relative amounts}

For quantitative comparison of different mRNA amounts in different cell lines, the assay should be proportional to different amounts of RNA but independent of different amounts of added labeled oligonucleotide. Oligonucleotides labeled at the $3^{\prime}$ end with terminal deoxytransferase were found unsuitable for these quantitative studies; their specific activity was too high to show saturation at useable radioactive concentrations. Oligonucleotides labeled at the $5^{\prime}$ end with $\mathrm{T} 4$ polynucleotide kinase and used at a mass concentration of $5 \mathrm{ng}$ per $\mathrm{ml}$ of hybridization mix were found to saturate the blot so that doubling the oligonucleotide concentration resulted in only a $7 \%$ increase in signal; quadrupling the oligonucleotide concentration resulted in a $20 \%$ increase. The amount of bound label was found to be proportional to different amounts of RNA over the range $1-5 \mu \mathrm{g}$ total RNA loaded. For the $\mathrm{H} 2 \mathrm{~A}$ genes listed in Table 1, oligonucleotides complementary to either the $5^{\prime}$ UTR or the $3^{\prime}$ UTR gave comparable results in these experiments (see Fig. 4). Each oligonucleo- tide hybridized to one band on Southern blots. The Betagen was used to quantitate the amounts of hybridized oligonucleotide. After quantitation, the blots were stripped and reprobed with labeled human H2A.X 5' UTR oligonucleotide for normalization. The amounts of label bound to the different blots were within $20 \%$ of each other, indicating that the efficiency of transfer and binding of the RNAs to the different blots had been similar.

\section{Chromosomal localization}

Southern blots of Eco RI digests of human genomic DNA or DNA from human-hamster somatic cell hybrids (Bios Corp.) were hybridized overnight with the same oligonucleotides as described above, except that in this case the oligonucleotides were labeled by $3^{\prime}$ tailing with $\left[\alpha^{-32}\right.$ P]dATP. Each $5^{\prime}$ or $3^{\prime}$ UTR oligonucleotide hybridized to one band and did not cross-hybridize to the hamster DNA.

\section{RESULTS}

\section{$H 2 A .1 b$ and $H 2 A .2$ cDNAs}

H2A.1b and H2A.2 cDNAs were isolated from a library designed to enrich for the cDNAs of replication-independent histone species, in particular that of H2A.X. When the library was screened with an $\mathrm{H} 2 \mathrm{~A}$ coding oligonucleotide, cDNAs for H2A.X (Mannironi et al., 1989) and several other $\mathrm{H} 2 \mathrm{~A}$ species were identified. Two of these, the H2A.1b and H2A.2 cDNAs, are diagrammed in Fig. 1. Analysis by $5^{\prime}$ extension showed that the cDNA clones for both H2A.1b and H2A. 2 were full length (data not presented).

Like the H2A.X cDNA, these two cDNAs contain the conserved histone stem-loop and the U7 snRNP binding sequences at internal sites. The H2A.2 cDNA contains a canonical stem-loop sequence (GGCUCU pairing with AGAGCC), whereas the H2A.1b cDNA contains a GU pair in its stem (GGCUCU pairing with AGGGCC). The H2A. 2 cDNA terminates with a poly(A) tract just downstream of the U7 snRNP binding sequence; there is a polyadenylation signal sequence AATAAA partially overlapping the sequence complementary to the U7 sn RNP RNA. 


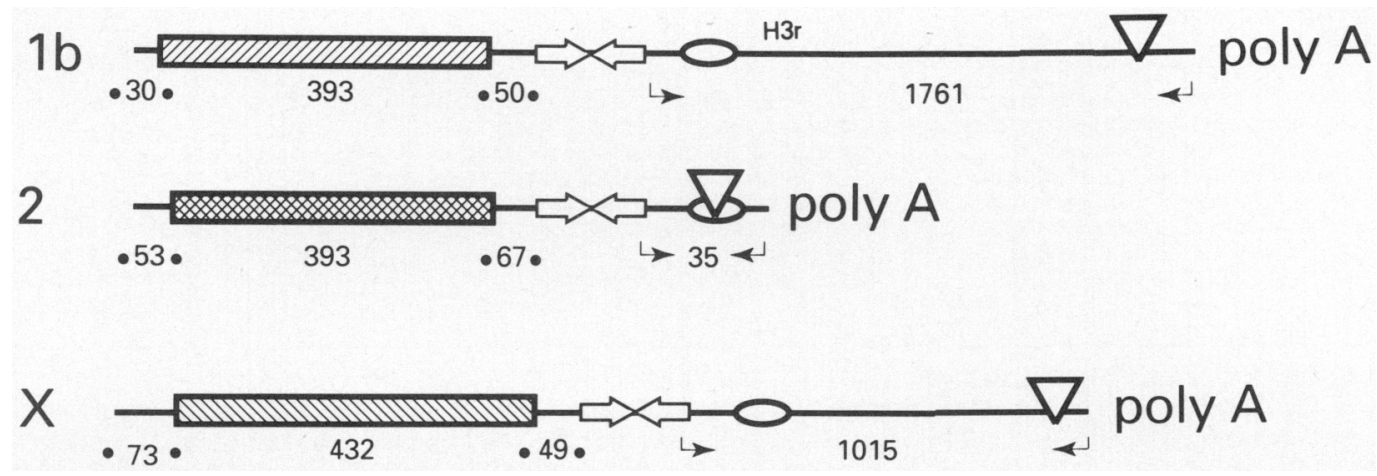

FIG. 1. The H2A.1b and H2A.2 cDNAs. The H2A.1b and H2A.2 cDNA structures are diagrammed and compared to that of the H2A.X cDNA. The placement of the coding regions (patterned rectangles), the stem-loops (head-to-head arrows), the U7 snRNP binding sequences (ovals), polyadenylation signals (inverted triangles), and poly(A) tails are shown. Numbers between dots below each diagram refer to the number of bases in each region of the cDNAs. Numbers between arrows below each diagram refer to the difference in length between the stem-loop and readthrough mRNAs [not including any poly(A) tracts].

The H2A.1b cDNA ends 1,758 bases downstream of the stem-loop sequence, also just beyond a polyadenylation signal sequence.

The long H2A.1b downstream region includes a region of Alu sequences 1,100-1,300 bases downstream of the stem-loop sequence and a remnant of an $\mathrm{H} 3$ coding sequence in a region 330 bases downstream of the stem-loop sequence. This remnant centers on 100 bases with about $75 \%$ identity of the nucleotide and amino acid sequences to amino acids 33-66 of human $\mathrm{H} 3$ coding sequences. Curiously, the nucleotide homology is higher, about $85 \%$, with chicken $\mathrm{H} 3 \mathrm{~s}$ in this region.

The H2A.2 cDNA has a high homology with a reported human H2A pseudogene (Marashi et al., 1984). In the 194-base overlap, the two sequences are identical except for the deletion of 12 bases for amino acids 8-11 in the pseudogene and 4 single base differences in the first 20 bases of the $5^{\prime}$ UTR. The high homology suggests that the pseudogene is of recent derivation.

Both the H2A.2 and H2A.1b cDNAs were isolated from the poly(A) cDNA library that was used to isolate the H2A.X cDNA. The H2A.X gene was found to encode two transcripts, a 0.6-kb stem-loop transcript typical of histone genes and a 1.6-kb readthrough polyadenylated transcript. The longer transcript is a significant and sometimes predominant fraction of the total H2A.X mRNA (Mannironi et al., 1989; Bonner et al., 1993). However, the H2A.2 and H2A.1b readthrough transcripts were only barely detectable under the circumstances examined (Fig. $2, A$ and $C$ ) in contrast to the $H 2 A . X 1.6 \mathrm{~kb}$ readthrough transcript (Fig. 2B). In addition, the readthrough transcripts of H2A.2 and H2A.1b decrease when DNA replication is inhibited while that of H2A.X does not (Fig. 2, lane 2 in each panel). These results show that the H2A.2 and H2A.1b genes appear to be typical histone genes, whereas the H2A.X gene exhibits anomalous behavior for a histone gene. Both the H2A.1b and H2A.2 mRNAs were found in polysomal pellets (data not presented), and, as shown below, were found to be the most abundant of the seven hu-

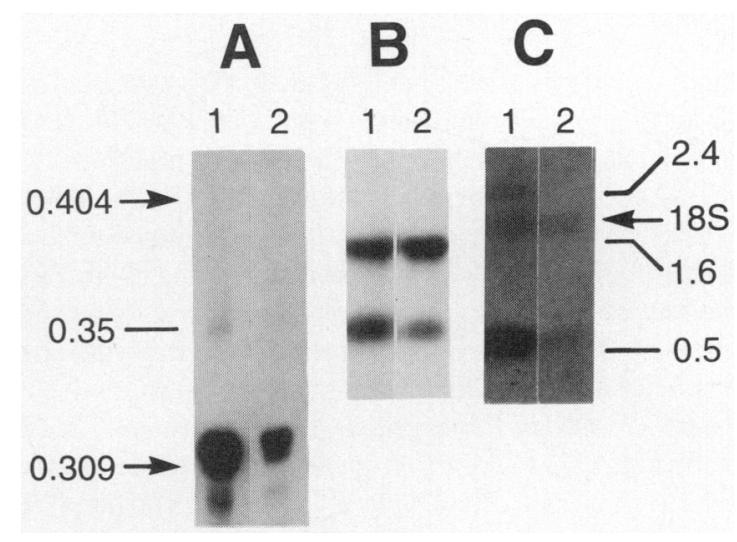

FIG. 2. Readthrough transcripts of $\mathrm{H} 2 \mathrm{~A}$ genes. Total RNA was isolated from HeLa cell cultures that had (lane 2 in each panel) or had not (lane 1 in each panel) been incubated with $1 \mathrm{mM}$ hydroxyurea for $30 \mathrm{~min}$. A. H2A.2 stem-loop $(0.312 \mathrm{~kb})$ and readthrough $(0.37 \mathrm{~kb})$ transcripts assayed by $\mathrm{S} 2$ nuclease protection of a probe from the cDNA labeled at an Xho I site 312 bases upstream from the end of the stem-loop mRNA. B. H2A.X stemloop (about $0.5 \mathrm{~kb}$ ) and readthrough mRNAs (1.6 kb) assayed with labeled $5^{\prime}$ UTR oligonucleotide on Northern blots. C. H2A.1b stem-loop (about $0.5 \mathrm{~kb}$ ) and readthrough mRNAs $(2.4 \mathrm{~kb})$ assayed with labeled $5^{\prime}$ UTR oligonucleotide on Northern blots. 18S denotes cross-hybridization to the 18s rRNA.

man H2A mRNAs analyzed. That these two cDNAs were isolated from polyadenylated mRNAs may reflect this high level of expression rather than the alternative $3^{\prime}$ end processing found for the H2A.X transcripts.

The amino acid sequences of the H2A.1b and H2A.2 histone proteins are compared to those of the other known H2As in Table 2. The differences among the members of the H2A family are localized to seven noncontiguous positions with the exception of H2A.X, which also differs in the carboxy-terminal region. H2A.1b has a sequence iden- 
Table 2. Amino Acid Differences Among the Human H2A Proteins.

\begin{tabular}{|c|c|c|c|c|c|c|c|c|}
\hline & & sub & utio & sequ & pos & & & \\
\hline H2A species & $\underline{6}$ & 16 & 38 & $40^{\circ}$ & $\underline{51}$ & $\underline{59}$ & $\underline{99}$ & $120+$ \\
\hline$\overline{H 2 A .1 a}$ & $\bar{Q}$ & $\bar{T}$ & $\bar{N}$ & $\bar{s}$ & $\bar{L}$ & $\bar{s}$ & $\bar{R}$ & ESHHKAKGK \\
\hline H2A.1d & Q & $T$ & $\mathbf{N}$ & $\mathbf{s}$ & $\mathbf{L}$ & $T$ & $\mathbf{R}$ & ESHHKAKGK \\
\hline $\mathrm{H} 2 \mathrm{~A} .1 \mathrm{~b} / \mathrm{C}$ & 0 & $\mathbf{T}$ & $\mathbf{N}$ & A & $\mathbf{L}$ & $T$ & $k$ & ESHHKAKGK \\
\hline H2A. 2 & Q & $\mathbf{s}$ & $\mathbf{N}$ & A & M & $\mathbf{T}$ & $\mathrm{k}$ & ESHHKAKGK \\
\hline H2A.X & $T$ & $\mathbf{s}$ & H & A & L & $\mathbf{T}$ & G & SATVGPKAPSGGKKATQASQEY \\
\hline
\end{tabular}

Translations of the open reading frames of the H2A genes and cDNAs listed in Materials and Methods.

tical to that of H2A.1c; these two sequences differ at positions 40 and 99 from that of $\mathrm{H} 2 \mathrm{~A} .1 \mathrm{~d}$ and at positions 16 and 51 from that of H2A.2. The H2A.2 has a methionine in place of leucine at position 51 .

\section{Chromosomal localization}

The replication-linked human histone genes have been localized to clusters on three chromosomes, numbers 1,6 , and 12 (Tripputi et al., 1986). The H2A.1b and H2A.2 genes, as well as other members of the H2A multigene family, were localized to specific human chromosomes in panels of somatic cell hybrids with oligonucleotides specific to the $5^{\prime}$ or $3^{\prime}$ UTRs of the different mRNAs. As shown in Table 3, the H2A.1b gene was located to chromosome 6 , as were the previously described genes for H2A.1a, H2A, 1c, and H2A.1d, consistent with these genes all being part of the histone gene cluster on that chromosome. The H2A.2 gene was localized to chromosome 1 with one discordancy. The H2A.X (Ivanova et al., submitted) and H2A.Z (Popescu et al., submitted) genes are not part of the histone gene clusters because they have been localized to chromosomes other than 1,6 , or 12 .

\section{Expression of different $H 2 A$ genes}

There are multiple genes known for each family of histone proteins, although the presence of pseudogenes (Marashi et al., 1984) and other partial remnants of genes as described above may lead to overestimates in the number of functional genes. To study whether the relative expression of individual members of the histone $\mathrm{H} 2 \mathrm{~A}$ gene family was dependent upon or independent of the type of proliferating cell, the relative amounts of mRNA encoding each of seven members of the H2A family in four cell lines were quantitated by hybridization of labeled oligonucleotides to Northern blots (Figs. 3 and 4). The method of Henderson et al. (1991) was used with some modifications. These researchers used oligonucleotides labeled to high specific activity by 3 ' tailing; however, with the more plentiful histone mRNAs, the $3^{\prime}$ tailed oligonucleotides had too high a specific activity to bind all the complementary sites at the radioactive concentrations used. With oligonucleotides 5' end-labeled at somewhat lower specific activity, the amounts of hybridization were found to be independent of the amount of added oligonucleotide over a four-fold range of concentrations.

The four human cell lines used in this study were Jurkat (a lymphoma line), $\mathrm{N}$-tera (an embryonic carcinoma line),
HeLa (a cervical carcinoma line), and IMR90 (a normal embryonic fibroblastic line). The first three bars (Fig. 4) in each set show the data from different experimental procedures with Jurkat RNA. The first bar shows the data taken from Northern blots prepared from agarose gels on which $1.25,2.5$, and $5 \mu \mathrm{g}$ of total RNA had been loaded in adjacent lanes. The amounts of hybridized oligonucleotides were found to increase linearly in proportion to the amounts of RNA loaded onto the gel; the slopes of those lines were used to calculate the relative amounts of the different mRNAs shown in the first bar.

The effect of oligonucleotide sequence on mRNA quantitation was examined by comparing the results obtained with two non-overlapping oligonucleotides complementary to the same mRNAs. Because the coding sequences of the histones are highly conserved, a second set of oligonucleotides complementary to the unique regions of the $3^{\prime}$ UTRs of the H2A.1a-d genes were prepared (Table 1). The second and third bars (Fig. 4) show that the quantitative results obtained with $5^{\prime}$ and $3^{\prime}$ UTR oligonucleotides agree within $25 \%$. The differences between the second and third bars, comparing $5^{\prime}$ and $3^{\prime}$ UTR oligonucleotides, are similar in magnitude to the differences between the first and second bars, comparing two independent determinations with $5^{\prime}$ UTR oligonucleotides. Thus, these results show that the quantitation is independent of the sequence of the oligonucleotide. The greatest difference found in these experiments was with the weakly expressed H2A.X mRNA; one of the determinations yielded results twice those of the other two, all of which were performed with the H2A.X 5' UTR oligonucleotide. We have no explanation for this result, but an error in the measurement of radioactivity incorporated into the H2A.X-specific oligonucleotide in this experiment could account for a difference of this kind. Taken together, the data in Fig. 4 show that these different experimental protocols all yielded comparable quantitative results.

The last four bars display the quantitative data taken from the blots shown in Fig. 3. Of the seven genes, the H2A. 2 is the major H2A mRNA producer in all four lines, contributing $35-45 \%$ of the total while the H2A.1a and H2A.1d contribute $4-8 \%$ in all four lines. Taken together, the results in Figs. 3 and 4 show that, whereas the replication-linked histone $\mathrm{H} 2 \mathrm{~A}$ genes are contributing different relative amounts of mRNA in any given cell line, the relative contribution of each replication-linked histone $\mathrm{H} 2 \mathrm{~A}$ gene is similar in the four cell lines.

This similarity among the four cell lines is maintained even though the amount of H2A mRNA relative to total RNA is different in the four cell lines, as shown in Fig. 3. 
Table 3. Chromosomal localization of Human Histone H2A Genes

\begin{tabular}{|c|c|c|c|c|c|c|c|c|c|}
\hline & \multicolumn{9}{|c|}{ Cell line } \\
\hline & 867 & 1,099 & 937 & 909 & 860 & 756 & 904 & 683 & 507 \\
\hline \multicolumn{10}{|c|}{$\begin{array}{l}\text { Human } \\
\text { chromosomes }\end{array}$} \\
\hline 1 & + & + & + & - & - & - & - & - & - \\
\hline 2 & - & - & - & - & - & - & - & - & - \\
\hline 3 & - & - & - & - & + & - & - & - & + \\
\hline 4 & - & - & - & - & - & - & - & - & - \\
\hline 5 & + & + & + & + & + & + & + & + & + \\
\hline 6 & - & - & - & + & + & + & + & - & - \\
\hline 7 & - & $\rightarrow$ & - & - & - & + & - & - & - \\
\hline 8 & - & - & - & + & - & - & - & - & - \\
\hline 9 & - & - & - & - & - & - & - & - & - \\
\hline 10 & - & - & - & - & + & - & - & - & - \\
\hline 11 & - & - & - & - & - & - & - & - & - \\
\hline 12 & - & - & - & - & - & + & + & + & + \\
\hline 13 & + & + & - & - & - & + & - & - & - \\
\hline 14 & + & - & + & + & - & + & - & + & + \\
\hline 15 & - & - & + & - & - & - & - & - & - \\
\hline 16 & - & - & - & - & - & - & + & - & - \\
\hline 17 & - & - & + & - & - & - & - & - & - \\
\hline 18 & + & - & - & - & - & - & - & - & - \\
\hline 19 & + & + & - & - & + & + & - & + & - \\
\hline 20 & - & - & - & - & - & + & - & - & + \\
\hline 21 & - & + & + & - & + & + & + & + & - \\
\hline 22 & - & + & - & - & - & - & - & + & + \\
\hline$X$ & - & - & - & + & - & - & - & - & - \\
\hline $\mathrm{Y}$ & - & - & - & - & - & + & + & - & + \\
\hline \multicolumn{10}{|c|}{ Probe } \\
\hline $1 \mathrm{a}$ & - & - & - & + & + & + & + & - & - \\
\hline $1 b$ & - & - & - & + & + & + & + & - & - \\
\hline $1 \mathrm{c}$ & - & - & - & + & + & + & + & - & - \\
\hline $1 \mathrm{~d}$ & - & - & - & + & + & + & + & - & - \\
\hline 2 & + & + & - & - & - & - & - & - & - \\
\hline
\end{tabular}

Procedures are described in Materials and Methods. Only those hamster-human hybrid cell lines with human chromosomes 1, 5, or 12 are listed. The other lines did not show any hybridization with these probes. Results show the presence $(+)$ or absence $(-)$ of a human chromosome or binding of oligonucleotide.

In these experiments, the Jurkat cell line had 5.5 times the H2A.2 mRNA as did the N-tera and IMR90 lines, and 3.5 times as much as the HeLa line. There were smaller differences among the cell lines with respect to the replication-independent H2A.Z mRNA; the Jurkat line had between 1.7 and 3 times the amount of the H2A.Z mRNA as did the others. Thus, the relative amount of the H2A.Z mRNA is about twice as much in the latter three cell lines as in the Jurkat line. The Jurkat cell line was the only one of the four grown in suspension, but whether this method of growth is responsible for the increased concentrations of histone mRNAs relative to total RNA is not known. The doubling times of the Jurkat cultures were measured at $21 \mathrm{hr}$, or about the same as that of attached HeLa cultures, suggesting that the Jurkat cultures were not proliferating at a faster rate than the HeLa cultures.
To ascertain whether or not the parallel differences of the H2A mRNA concentrations in these four cell lines were exhibited by all mRNAs, the same Northern blots were hybridized with an oligonucleotide to Human HLA class I mRNA (Parham et al., 1989). Jurkat, N-tera, and HeLa cell RNA were found to contain similar amounts of HLA mRNA, whereas IMR90 cell RNA contained much larger amounts of HLA mRNA, a pattern different from that of the H2A mRNAs. In addition, RNA preparations from quiescent IMR90 cell cultures had similar amounts of HLA mRNA as did proliferating IMR90 cell cultures, whereas the H2A mRNAs had decreased to much lower concentrations in the quiescent cultures (data not presented). These changes show that the parallel differences in the concentrations of these H2A mRNAs in the four cell lines are not shown by other nonhistone mRNAs. 


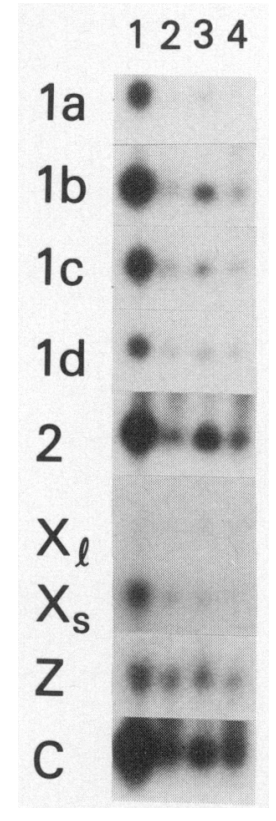

FIG. 3. The relative concentrations of seven $\mathrm{H} 2 \mathrm{~A}$ mRNAs in four cell lines. The cell lines are: lane 1, Jurkat; lane 2, N-tera; lane 3, HeLa; and lane 4, IMR90. Jurkat cell cultures in suspension were diluted to $2 \times 10^{5}$ cells $/ \mathrm{ml}$ and harvested for RNA when the cell number reached about $8 \times 10^{5}$ cells $/ \mathrm{ml}$ (Jurkat cell cultures exhibited exponential growth until about $12 \times 10^{5}$ cells $/ \mathrm{ml}$ ). The other three lines were grown attached and harvested when cultures were two-thirds to three-fourths confluent. Total RNA $(5 \mu \mathrm{g})$ was loaded onto each lane of $1 \%$ agarose gels with formaldehyde. Gels were electroblotted after staining briefly with ethidium bromide to visualize the $18 \mathrm{~S}$ and $28 \mathrm{~S}$ rRNA bands. Identically prepared blots were hybridized and washed as described in Materials and Methods with labeled oligonucleotides for the indicated mRNAs. The H2A.1a-d oligonucleotides (1a-1d) were from the $3^{\prime}$ UTRs (Table 1), and the H2A.2 (2) was from the $5^{\prime}$ UTR. The H2A.X oligonucleotide was from the $5^{\prime}$ UTR and bound to both the 0.6-kb $\left(X_{s}\right)$ and the 1.6-kb $\left(X_{1}\right)$ mRNAs. The H2A.Z (Z) oligonucleotide was from a portion of the coding region that differed from the coding regions of the other H2A mRNAs. The H2A consensus oligonucleotide (C) was derived as described in Materials and Methods and Table 1. The autoradiograph was exposed to visualize all the relevant bands without overexposing the darkest.

These values of histone mRNA relative to total RNA cannot be used to compare histone mRNA per replicating cell for two reasons. First, the amounts of histone mRNA are normalized to total RNA; the values of total RNA per cell could vary between cell lines. Second, these differences in amounts of histone mRNA relative to total RNA could be the result of differences in the fraction of cell culture in $\mathrm{S}$ phase as well as the amount of H2A mRNA per S-phase cell.

While the relative contributions of the different replication-linked histone H2A genes are similar in all four cell lines, there is some variation. For example in Jurkat cell cultures, there is about 1.5 times as much H2A.2 mRNA as there is H2A.1b mRNA, while in the other lines the ratio is 2.1-2.4. However, as seen in Fig. 4, these differences are of smaller magnitude and do not substantially alter the overall finding that each $\mathrm{H} 2 \mathrm{~A}$ gene appears to be contributing a similar relative amount of $\mathrm{H} 2 \mathrm{~A}$ mRNA in each of the four cell lines.

\section{Estimate of the amount of $H 2 A \mathrm{mRNA}$}

To estimate the total amount of $\mathrm{H} 2 \mathrm{~A}$ mRNA relative to the sum of the seven H2A mRNAs studied here, an H2A oligonucleotide to the most highly conserved coding region the H2A mRNAs was designed (Table 1). In this region, with the exception of the H2A.Z mRNA, it was possible to design an oligonucleotide with similar length and $T_{\mathrm{m}}$ parameters to those of the other oligonucleotides, allowing only one to three GU mismatches. When hybridized to Northerns of the four cell lines, this oligonucleotide gave values of H2A mRNA concentrations 2.1 as high as the sum of the six stem-loop mRNAs in Jurkat cells and similar ratios for the other cell lines. When hybridized to a Southern of Eco RI-digested human genomic DNA (Fig. 5), this oligonucleotide detected 16 bands, six of which were assigned to the stem-loop histone genes used in this study. Some of the other bands could be due to pseudogenes and other remnants, but this result is consistent with the presence of at least several other active $\mathrm{H} 2 \mathrm{~A}$ genes in these cell lines. The estimate of human H2A genes with this oligonucleotide is also consistent with other estimates of histone genes in mammals (Heintz, 1991).

\section{Linkage of H2A mRNA concentrations to DNA and protein synthesis}

The five replication-linked H2A mRNA species decrease to $5-13 \%$ of their uninhibited levels when DNA synthesis is inhibited and increase to $500-730 \%$ when protein synthesis is inhibited (data not presented). These ratios are similar for the most highly expressed H2A.2 gene and the least highly expressed H2A.1a and H2A.1d genes. Regulatory mechanisms at both the transcriptional and translational levels (Heintz et al., 1983; Sittman et al., 1983) are known to make significant contributions to the changes in amounts of histone mRNA when DNA or protein synthesis is inhibited (Bonner et al., 1993). These data then suggest that the regulation of the rates of transcription of these histone genes when DNA or protein synthesis is inhibited may be independent of the relative expression of the genes.

\section{DISCUSSION}

We have measured the amounts of seven H2A mRNAs in four proliferating human cells lines of diverse origin. While the seven histone mRNAs used in this study are not the total H2A mRNA in these cell lines, the data from the consensus $\mathrm{H} 2 \mathrm{~A}$ oligonucleotide suggests that they account for a sizeable fraction. These genes include two replica- 


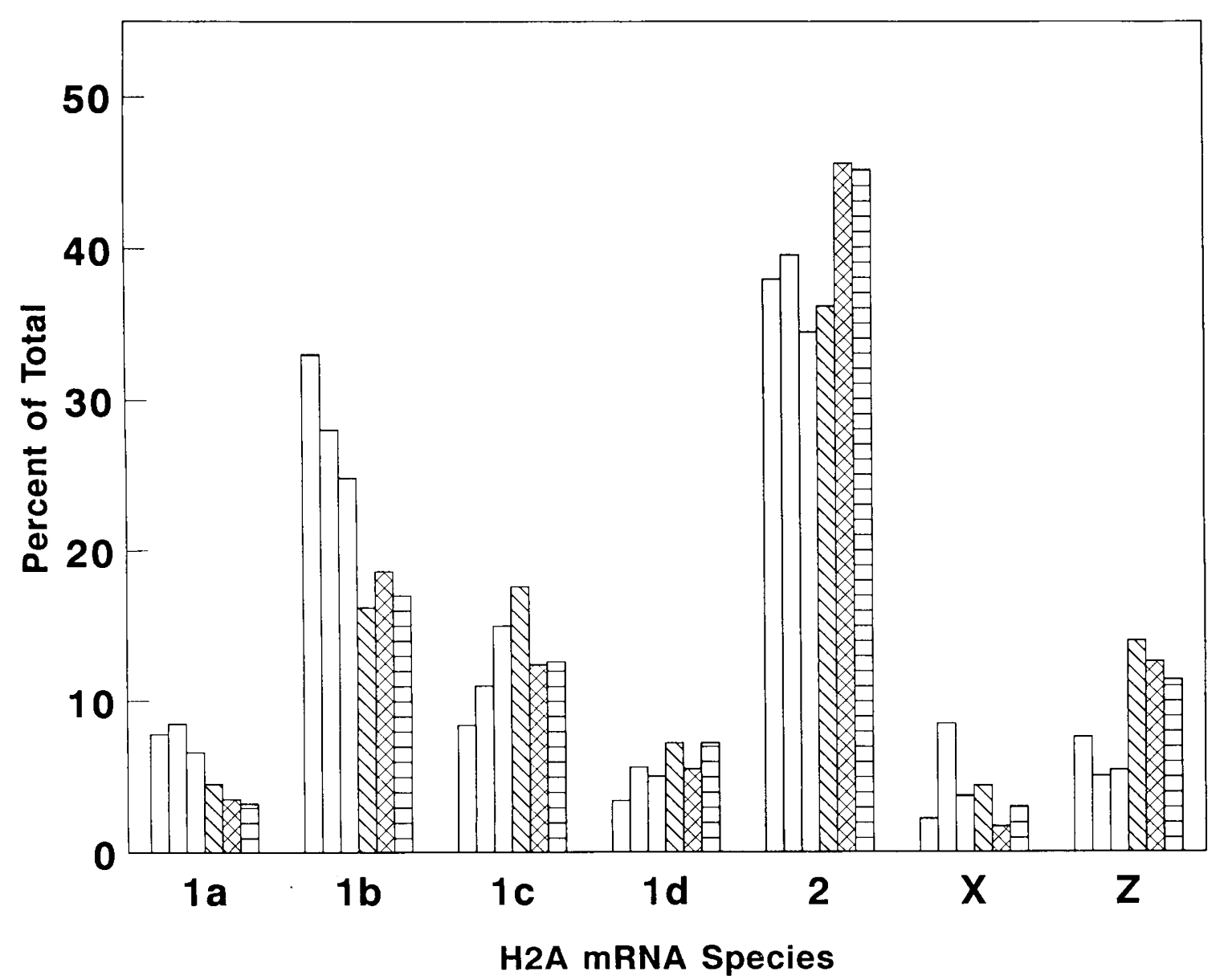

FIG. 4. Quantitation of the relative concentrations of seven $\mathrm{H} 2 \mathrm{~A}$ mRNAs. Quantitation of label bound to the Northern blots shown in Fig. 3 as well as to other blots was performed with the Betascope Analyzer. After overnight collection, the amount of labeled oligonucleotide bound by each RNA sample was measured; backgrounds were measured from nearby regions and subtracted. The amount of bound label was then normalized for the specific activity of the labeled oligonucleotide. Those values were summated and used as the $100 \%$ ordinate value. The first three unpatterned bars in each group are for Jurkat mRNAs; the last three patterned bars are for the other cell lines. The first bar is the relative amount of each mRNA from blots with $1.25,2.5$, and $5 \mu \mathrm{g}$ of total RNA in adjacent lanes. Label bound was proportional to the RNA loading. The second bar is the relative amount of each mRNA from blots with $5 \mu \mathrm{g}$ total RNA per lane with $5^{\prime}$ UTR oligonucleotides as probes. The last four bars are the relative amount of each mRNA from blots with $5 \mu \mathrm{g}$ total RNA from Jurkat (third unpatterned), N-tera (diagonally patterned), HeLa (cross-hatch patterned), and IMR90 (horizontally patterned) cell cultures per lane probed with labeled $3^{\prime}$ or $5^{\prime}$ UTR oligonucleotides as described in Fig. 3.

tion-independent $\mathrm{H} 2 \mathrm{~A}$ genes and five replication-dependent $\mathrm{H} 2 \mathrm{~A}$ genes. The latter include a highly expressed H2A. 2 gene that accounts for $35-45 \%$ of the sum of the seven H2A mRNA in these cell lines and much less highly expressed H2A.1a and H2A.1d genes that account for less than $10 \%$.

Four of the H2A mRNAs quantitated encode H2A.1 proteins while one mRNA each encodes an H2A.2, H2A.X, and H2A.Z protein; these four species are separable from each other and other contaminating proteins by two-dimensional gel electrophoresis. When the relative synthetic rates of the four $\mathrm{H} 2 \mathrm{~A}$ protein species are measured by labeled $\left[{ }^{14} \mathrm{C}\right]$ lysine incorporation into proliferating Jurkat cell cultures, the H2A.1 protein species were found to account for $68 \%$ of the total label in $\mathrm{H} 2 \mathrm{~A}$ pro- tein species, compared to $52 \%$ for the relative concentration of the H2A.1a-d mRNA species (average of the three determinations of Jurkat relative mRNA concentrations); the H2A. 2 protein accounted for $26 \%$ of the nascent $\mathrm{H} 2 \mathrm{~A}$ protein compared to $37 \%$ for the H2A.2 mRNA; for H2A.X, the values were $2 \%$ for the protein versus $4.8 \%$ for the mRNA; for H2A.Z the values were $4 \%$ for the protein versus $6 \%$ for the mRNA. Thus, for $\mathrm{H} 2 \mathrm{~A} .1$, the relative protein synthetic rate was more than the relative mRNA concentrations of H2A.1 mRNAs, while for the others the relative mRNA concentrations were more than the relative protein synthetic rates. Assuming that the different histone mRNAs are translated at similar rates, these values suggest that $\mathrm{H} 2 \mathrm{~A}$ genes encoding $\mathrm{H} 2 \mathrm{~A} .1$ proteins are underrepresented in these seven known $\mathrm{H} 2 \mathrm{~A}$ genes. 


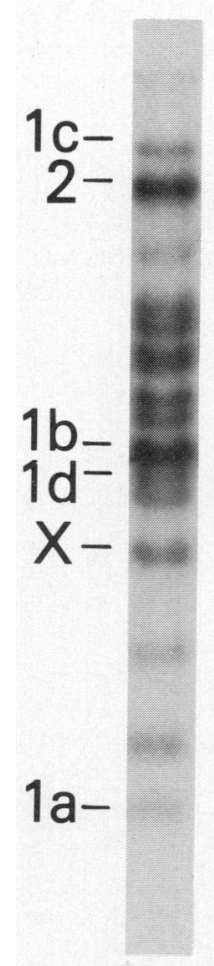

FIG. 5. Southern blot of human genomic DNA digested with Eco RI. A blot of Eco RI-digested human genomic DNA (Bios Corp.) was hybridized with the H2Acod or other $5^{\prime}$ UTR oligonucleotides that had been $3^{\prime}$ labeled with $\left[\alpha^{-32} \mathrm{P}\right] \mathrm{dATP}$ and terminal deoxytransferase. Other techniques are described in Materials and Methods.

In contrast to the synthesis of large amounts of histone proteins in concert with DNA replication, histone proteins may be synthesized in the absence of DNA synthesis in germ-line cells and nonproliferating somatic cells. In differentiating murine leukemia cells, histone synthesis decreases about five-fold and, during this time, there are changes in the composition of the H2A and other histone complements (Grove and Zweidler, 1984). Over a 6-day induction period, the amount of H2A.1 decreases from $47 \%$ to $30 \%$ of total H2A protein with increases in H2A.2 and H2A.X, suggesting that changes in relative gene expression have occurred. In nonproliferating somatic cells such as differentiated HL60 cells (Stein et al., 1989) and quiescent normal human fibroblasts (Wright et al., 1992), histone gene transcription is greatly downregulated; however, a small amount of mRNA remains in these two types of cells that is the same size as the stem-loop mRNAs but is not sensitive to inhibitors synthesis (Mannironi and Bonner, unpublished results). These findings suggest that a low rate of replication-linked histone mRNA synthesis independent of DNA replication may be responsible for the synthesis of certain histone species in nonproliferating cells.

In germ-line cells, the use of replication-linked histone genes for synthesis in the absence of DNA replication has been clearly demonstrated. In Xenopus oocytes and chicken testis, histone mRNAs have been described that contain the stem-loop internally and terminate further downstream in a poly(A) tail (Ballantine and Woodland, 1985; Chambers and Old, 1988; Challoner et al., 1989). Transcripts from a chicken H2B gene were found in somatic cells processed to a 500-base mRNA terminating in the $3^{\prime}$ stem-loop and in spermatid cells processed to an 800-base mRNA terminating with a poly(A) tail beginning 26-28 bases beyhond the stem-loop. Thus, the structure of this germ-line H2B mRNA is similar in structure to the H2A.2 readthrough cDNA reported here.

Thus, it appears that individual members of a histone gene family may be expressed in germ-line cells and nonproliferating somatic cells as well as in proliferating somatic cells, and expression under these differing cellular environments may involve different transcriptional control factors. However, in different types of proliferating somatic cells, the evidence with the H2A gene family suggests that the relative expression of each member of a histone gene family is independent of the type of cell.

\section{REFERENCES}

ALBIG, W., KARDALINOU, E., DRABENT, B., ZIMMER, A., and DOENECKE, D. (1991). Isolation and characterization of two human $\mathrm{H} 12$ histone genes with clusters of core histone genes. Genomics 10, 940-948.

ALTSCHUL, S.F., GISH, W., MILLER, W., MYERS, E.W., and LIPMAN, D.J. (1990). Basic local alignment search tool. J. Mol. Biol. 215, 403-410.

ANDREWS, P.W., DAMJANOV, I., SIMON, D., BANTING, G., DRACOPOLI, N.C., and FOGH, J. (1984). Pluripotent embryonal carcinoma clones derived from the human teratocarcinoma cell line Tera-2. Lat. Invest. 50, 147-162.

BALLANTINE, J.E.M., and WOODLAND, H.R. (1985). Polyadenylation of histone mRNA in Xenopus oocytes and embryos. FEBS Lett. 180, 224-228.

BANDYOPADHYAY, R., STEIN, G., and STEIN, J. (1987). Coordinate turnover of nuclear and cytoplasmic histone messenger RNA following inhibition of DNA replication in Hela S3 cells. Biochemistry 26, 2938-2944.

BAUMBACH, L.L., MARASHI, F., PLUMB, M., STEIN, G., and STEIN, J. (1984). Inhibition of DNA replication coordinately reduces cellular levels of core and $\mathrm{H} 1$ histone mRNAs: Requirement for protein synthesis. Biochemistry 23, 1618-1625.

BONNER, W., MANNIRONI, C., ORR, A., PILCH, D., and HATCH, C. (1993). Histone H2A.X gene transcription is regulated differently than transcription of other replication-linked histone genes. Mol. Cell. Biol. 13, 984-992.

CHALLONER, P.B., MOSS, S.B., and GROUDINE, M. (1989). Expression of replication-dependent histone genes in avian spermatids involves an alternate pathway of mRNA 3'-end formation. Mol. Cell. Biol. 9, 902-913.

CHAMBERS, A., and OLD, R. (1988). RNA 3' cleavage and polyadenylation in oocytes and unfertilized eggs of Xenopus laevis. Dev. Biol. 125, 237-245.

DALTON, S., ROBINS, A.J., HARVEY, R.P., and WELLS, J.R.E. (1989). Transcription from the intron-containing chicken histone H2A.F gene is not S-phase regulated. Nucleic Acids Res. 17, 1745-1756. 
DOBNER, T., WOLF, I., MAI, B., and LIPP, M. (1991). A novel divergently transcribed human histone $\mathrm{H} 2 \mathrm{~A} / \mathrm{H} 2 \mathrm{~B}$ gene pair. DNA Sequencing and Mapping 1, 409-413.

GRAVES, R.A., PANDEY, N.B., CHODCHOY, N., and MARZLUFF, W.F. (1987). Translation is required for regulation of histone mRNA degradation. Cell 48, 615-626.

GROVE, G.W., and ZWEIDLER, A. (1984). Regulation of nucleosomal core histone variant levels in differentiating murine erythroleukemia cells. Biochemistry 23, 4436-4443.

HATCH, C.L., and BONNER, W.M. (1988). Sequence of cDNAs for mammalian H2A.Z, an evolutionarily diverged but highly conserved basal histone $\mathrm{H} 2 \mathrm{~A}$ isoprotein species. Nucleic Acids Res. 16, 1113-1124.

HATCH, C.L., and BONNER, W.M. (1990). The human histone H2A.Z gene: Sequence and regulation. J. Biol. Chem. 265, 15211-15218.

HEINTZ, N., SIVE, H.L., and ROEDER, R.G. (1983). Regulation of human histone gene expression: Kinetics of accumulation and changes in the rate of synthesis and in the half-lives of individual histone mRNAs during the Hela cell cycle. Mol. Cell. Biol. 3, 539-550.

HEINTZ, N. (1991). The regulation of histone gene expression during the cell cycle. Bioch. Biophys. Acta 1088, 327-339.

HEINTZ, N., SIVE, H.L., and ROEDER, R.G. (1983). Regulation of human histone gene expression: Kinetics of accmulation and changes in the rate of synthesis and in the half-lives of individual histone mRNAs during the Hela cell cycle. Mol. Cell. Biol. 3, 539-550.

HENDERSON, G.S., CONARY, J.T., DAVIDSON, J.M., STEWART, S.J., HOUSE, F.S., and MCCURLEY, T.L. (1991). A reliable method for Northern blot analysis using synthetic oligonucleotide probes. BioTechniques 10, 190-197.

HUH, N.-E., HWANG, I., LIM, K., YOU, K.-H., and CHAE, C.-B. (1991). Presence of a bi-directional S phase-specific transcription regulatory element in the promoter shared by testisspecific TH2A and TH2B histone genes. Nucleic Acids Res. 19, 93-98.

HURT, M., CHODCHOY, N., and MARZLUFF, W. (1989). The mouse histone H2A.2 gene from chromosome 3. Nucleic Acids Res. 17, 8876.

MANNIRONI, C., BONNER, W.M., and HATCH, C.L. (1989). H2A.X, a histone isoprotein with a conserved C-terminal sequence, is encoded by a novel mRNA with both replication type and poly A $3^{\prime}$ processing signals. Nucleic Acids Res. 17, 9113-9126.

MARASHI, F., PROKOPP, K., STEIN, J., and STEIN, G. (1984). Evidence for a human histone gene cluster containing H2B and H2A pseudogenes. Proc. Natl. Acad. Sci. USA 81, 1936-1940.

MOSS, S.B., CHALLONER, P.B., and GROUDINE, M. (1989). Expression of a novel histone $2 \mathrm{~B}$ during mouse spermiogenesis. Dev. Biol. 133, 83-92.

OSLEY, M.A. (1991). The regulation of histone synthesis in the cell cycle. Annu. Rev. Biochem. 60, 827-861.

PANTAZIS, P., and BONNER, W.M. (1984). Specific alterations in the pattern of histone 3 synthesis during conversion of human leukemic cells to terminally differentiated cells in culture. Differentiation 28, 186-190.

PARHAM, P., BENJAMIN, R.J., CHEN, B.P., CLAYBERGER, C., ENNIS, P.D., KRENSKY, A.M., LAWLOR, D.A., LITTMAN, D.R., NORMENT, A.M., ORR, H.T.,
SALTER, R.D., and ZEMMOUR, J. (1989). Diversity of class I HLA molecules: Functional and evolutionary interactions with $T$ cells. Cold Spring Harb. Symp. Quant. Biol. 54, 529-543.

SAMBROOK, J., FRITSCH, E.F., and MANIATIS, T. (1989). Molecular Cloning, A Laboratory Manual, 2nd ed. (Cold Spring Harbor Laboratory Press, Cold Spring Harbor, NY).

SITTMAN, D.B., GRAVES, R.A., and MARZLUFF, W.F. (1983). Histone mRNA concentrations are regulated at the level of transcription and mRNA degradation. Proc. Natl. Acad. Sci. USA 80, 1849-1853.

STEIN, G.S., LIAN, J.B., STEIN, J.L., BRIGGS, R., SHALHOUB, V., WRIGHT, K.L., PAULI, U., and VAN WIJNEN, A.J. (1989). Altered binding of human histone gene transcription factors during the shutdown of proliferation and the onset of differentiation in HL60 cells. Proc. Natl. Acad. Sci. USA 86, 1865-1869.

STIMAC, E., GROPPI, V.E., JR., and COFFINO, P. (1984). Inhibition of protein synthesis stabilizes histone mRNA. Mol. Cell. Biol. 4, 2082-2087.

TRIPPUTI, P., EMANUEL, B.S., CROCE, M., GREEN, L.G., STEIN, G.S., and STEIN, J.L. (1986). Human histone genes map to multiple chromosomes. Proc. Natl. Acad. Sci. USA 83, 3185-3188.

WELLS, D., and KEDES, L. (1985). Structure of a human histone cDNA: Evidence that basally expressed histone genes have intervening sequences and encode polyadenylated mRNAs. Proc. Natl. Acad. Sci. USA 82, 2834-2838.

WELLS, D., and MCBRIDE, C. (1989). A comprehensive compilation and alignment of histones and histone genes. Nucleic Acids Res. 17(Suppl.), r311-346.

WELLS, D., and BROWN, D. (1991). Histone and histone gene compilation and alignment update. Nucleic Acids Res. 19 (Suppl.) r2173-2188.

WRIGHT, K.L., DELL'ORCO, R.T., VAN WIJNEN, A.J., STEIN, J.L., and STEIN, G.S. (1992). Multiple mechanisms regulate the proliferation specific histone gene transcription factor, HiNF-D, in normal human diploid fibroblasts. Biochemistry 31, 2812-2818.

WU, R.S., and BONNER, W.M. (1985). Mechanism for the differential sensitivity of the chromosome and growth cycles to the rate of protein synthesis. Mol. Cell. Biol. 5, 2959-2966.

WU, R.S., TSAI, S., and BONNER, W.M. (1982). Patterns of histone variant synthesis can distinguish $G_{0}$ from $G_{1}$ cells. Cell 31, 367-374.

WU, R.S., TSAI, S., and BONNER, W.M. (1983). Changes in histone $\mathrm{H} 3$ composition and synthesis pattern during lymphocyte activation. Biochemistry 22, 3868-3873.

Address reprint requests to: Dr. William Bonner Laboratory of Molecular Pharmacology Developmental Therapeutics Program Division of Cancer Treatment National Cancer Institute, NIH Building 37, Room 5D17 Bethesda, MD 20892

Received for publication June 28, 1993; accepted August 26, 1993. 